\title{
Engaging male partners of adolescent girls and young women in HIV services in Malawi: Findings from DREAMS implementation science research
}

Project SOAR

Follow this and additional works at: https://knowledgecommons.popcouncil.org/departments_sbsr-hiv

Part of the Demography, Population, and Ecology Commons, Family, Life Course, and Society Commons, International Public Health Commons, Maternal and Child Health Commons, and the Women's Health Commons How does access to this work benefit you? Let us know!

\section{Recommended Citation}

Project SOAR. 2018. "Engaging male partners of adolescent girls and young women in HIV services in Malawi: Findings from DREAMS implementation science research," Project SOAR Results Brief.

Washington, DC: Population Council. 


\section{Engaging Male Partners of Adolescent Girls and Young Women in HIV Services in Malawi: Findings from DREAMS implementation science research}

Adolescent girls and young women (AGYW) aged 15-24 remain at high risk for HIV in Malawi where HIV prevalence in this age group is 3.4 percent. $^{1}$ National estimates, however, mask geographic variations. For example, Project SOAR found that HIV prevalence among AGYW aged $17-23$ is 6.3 percent and HIV incidence from 2010-2013 is 9.7 per 1,000 in Machinga and Balaka districts. ${ }^{2}$

An important contributor to AGYW's vulnerability to HIV are power differentials in their sexual relationships with male partners. These differentials reduce the ability of AGYW to successfully negotiate condom use with male partners who are exposed to HIV through their often larger sexual networks. ${ }^{3}$ Moreover, men are often reluctant to access HIV prevention, care, and treatment services, including HIV testing services (HTS), antiretroviral therapy (ART), and voluntary medical male circumcision (VMMC). ${ }^{4}$ Modeling exercises have indicated that reductions in HIV incidence can be attained among AGYW with effective implementation and coverage of VMMC and ART for men. ${ }^{5}$ Therefore, engaging male partners of AGYW is important in reducing HIV incidence among AGYW.

Project SOAR, in collaboration with the Center for Reproductive Health at the University of Malawi College of Medicine, conducted qualitative research in two districts implementing DREAMS programming ${ }^{1}$, Zomba and Machinga, to:

${ }^{1}$ The DREAMS (Determined, Resilient, Empowered, AIDS-free, Mentored and Safe) partnership is an ambitious public-private partnership to reduce rates of HIV among AGYW in 10 sub-Saharan African countries. For more information go to: usaid.gov/what-we-do/ global-health/hiv-and-aids/technical-areas/dreams

\section{KEY FINDINGS}

- AGYW's male partners are diverse in their demographic characteristics and in the locations where they meet AGYW.

- Men identify HIV service barriers as fear of testing positive, stigma, long waiting times, lack of privacy and confidentiality, and the use of female healthcare workers to provide certain services.

- Emphasizing men's health and well-being and engaging their peers and partners in health promotion messages facilitates their HIV service use.

- Men want health communication messages and services that:

- Meet their needs and answer their questions.

- Are delivered by male providers.

- Are provided at home and other venues they frequent.

- Incorporate mass media and other technologies.

- Identify and locate the types of men who have sexual relationships with AGYW.

- Understand the challenges to and facilitators of accessing HIV services (e.g., HTS, VMMC, ART) among AGYW's male partners.

- Identify strategies to reach and engage male partners of AGYW in HIV services. 


\section{METHODS}

We conducted two community mapping exercises with AGYW and two with community opinion leaders (e.g., village chiefs, religious leaders, healthcare workers [HCWs]). The exercises aimed to identify locations where AGYW meet male sexual partners and the types of men who have sexual relationships with AGYW.

The study team then visited the identified venues and invited men, aged 18 and older, to participate in focus group discussions (FGDs). Men were eligible to participate if they were in a relationship with a woman between the ages of 15 and 24. A total of 16 FGDs, 8 in each district, was conducted. The FGD guide focused on:

- Men's experiences with accessing HIV services.

- What they wanted from HIV services.

- Reasons men may or may not access HIV services.

- Specific strategies that would encourage men to access HIV services.

The study was approved by the Population Council Institutional Review Board (New York, USA) and the College of Medicine Research and Ethics Committee (CoMREC) at the University of Malawi.
COMMUNITY MAPPING RESULTS

\section{AGYW meet their male partners in a wide variety of locations.}

\begin{tabular}{|lcc|}
\hline & Machinga & Zomba \\
Initiation ceremonies for boys & $\mathrm{X}$ & \\
Rest houses/lodges & $\mathrm{X}$ & $\mathrm{X}$ \\
Markets/trading centers & $\mathrm{X}$ & $\mathrm{X}$ \\
Bars & $\mathrm{X}$ & $\mathrm{X}$ \\
Construction company offices & $\mathrm{X}$ & \\
Along the road/hills/bushes & $\mathrm{X}$ & $\mathrm{X}$ \\
In schools/teachers' homes & $\mathrm{X}$ & $\mathrm{X}$ \\
Riverbanks & $\mathrm{X}$ & \\
Football grounds & $\mathrm{X}$ & $\mathrm{X}$ \\
Estates & & $\mathrm{X}$ \\
Church & $\mathrm{X}$ & $\mathrm{X}$ \\
Village breweries & & $\mathrm{X}$ \\
Health centers & & $\mathrm{X}$ \\
Video showrooms & & $\mathrm{X}$ \\
\hline
\end{tabular}

Source: Community mapping exercises with AGYW and opinion leaders.

Figure 1 shows a map created by AGYW participants. In this example, AGYW reported meeting male partners who were vendors at markets, bars, hostels, bushes and on the main

\section{Figure 1 Map showing where AGYW meet different types of male partners}

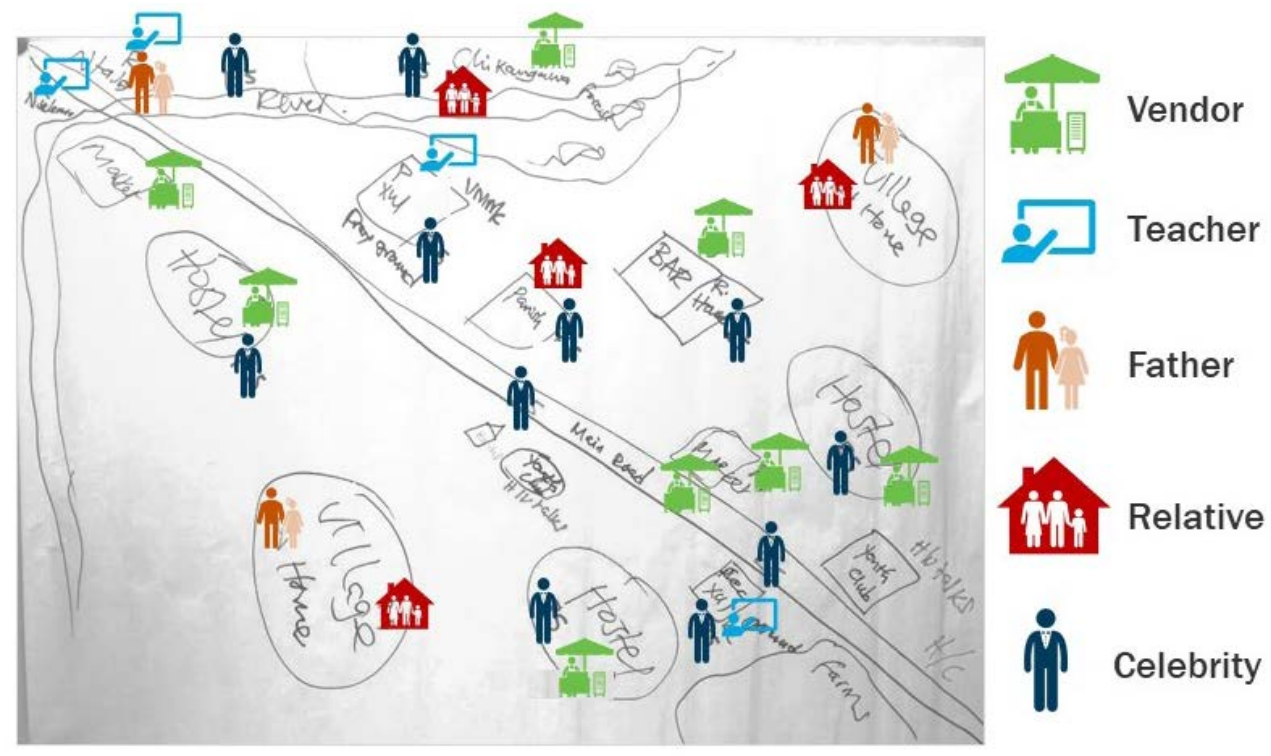


Figure 2 Who are the male partners that participated in the FGDs?
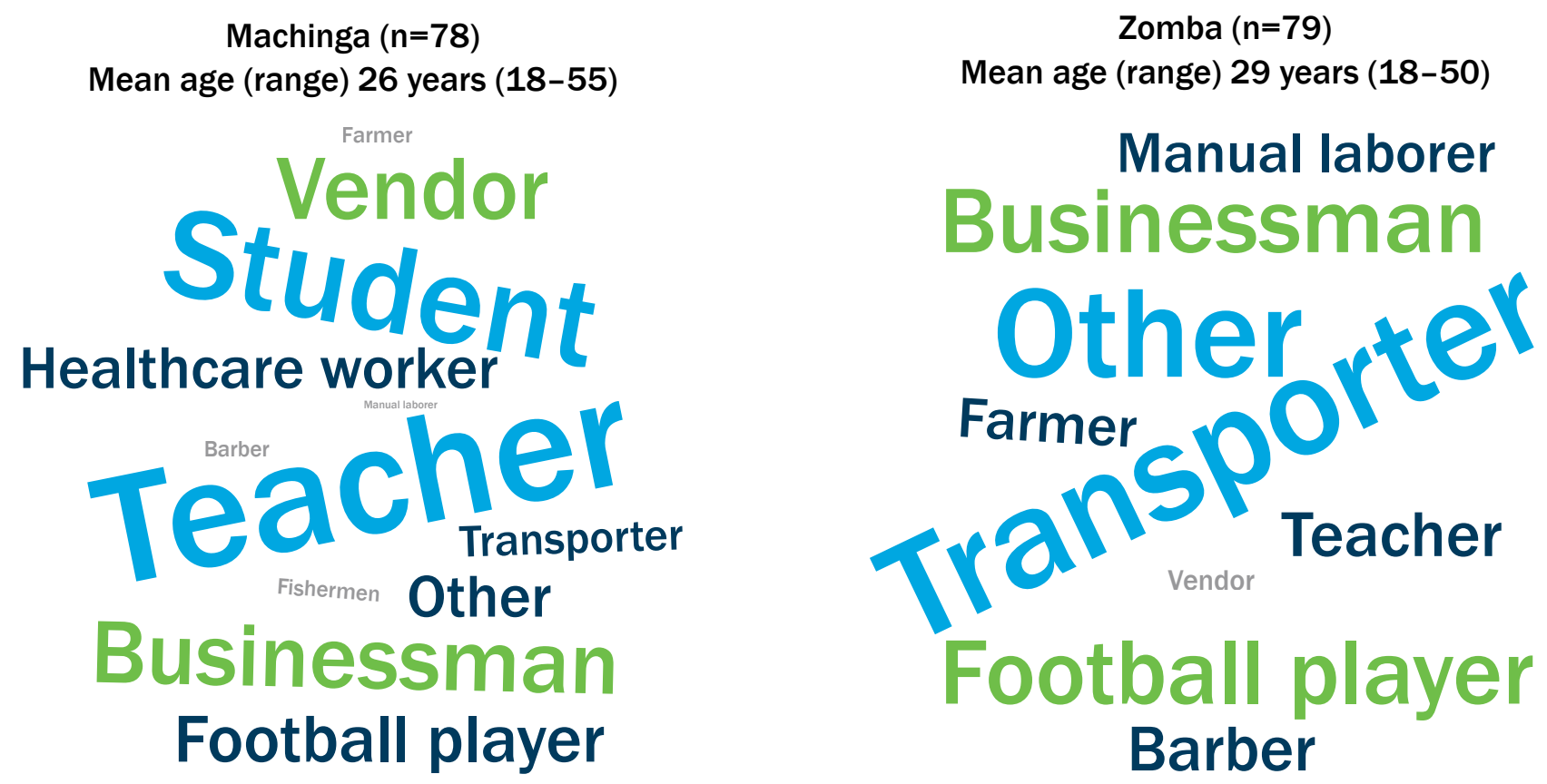

Note: The size of men's occupations is in proportion to their representation in the FGDs.

road, while they met male partners who were teachers at schools, rest houses, football grounds, and hostels.

\section{FOCUS GROUP DISCUSSION RESULTS}

Figure 2 illustrates the occupations of the male partners that participated in the FGDs.

\section{Why don't men access HIV services?}

Fear of testing positive: For many men, being positive equated death. They feared a reduced quality of life would result from living with HIV. Prominent was the concern of relationship dissolution, whereby if the man tests positive but his wife or partner tests negative, the relationship will end.

"Most of the time when men go for testing they tend to be worried that if I test HIV positive they change their mode saying that I am dead, so they tend to be afraid and shy and do not go but they do not know that they can find themselves a bright future after going there."

-Zomba, 25, Sells Chips

"Mmm, I remember I had an uncle who at one point went to the hospital together with his sexual partner where they got tested for HIV/AIDS. When the results came out it was discovered that my uncle was found HIV positive while the female partner was found HIV negative. As a result the marriage ended. So most of the time people are afraid of this outcome."

-Machinga, 25, Barber

Stigma: Men described both internalized and externalized stigma being barriers to service use. Internally, some men noted that they feel ashamed accessing the services. Externally, they feared being treated differently by others if they were living with HIV.

“...there is a myth which says that when a person had HIV testing and the results are that person is HIV positive then that 
person will be segregated...and people will be talking about me in the community; therefore to avoid being discriminated they prefer to remain the way they are without going for HIV testing. Also they know that when they will be living they will have stress and they will not have friends who they can chat with and at their home there will be insufficient support for him; then it is better just to stay as the way he used to do.

-Machinga, 52, Teacher

\section{Lack of privacy and confidentiality: Men}

explained that HCWs are from their community and if they were to access testing services and test positive, the HCWs would reveal their status to their community. They also noted there are specific days when health facilities serve people living with HIV and by this schedule, people in the community automatically become aware of your status. These factors amplified stigma and discrimination. As a result, men chose either to not access services or to travel outside of their communities for services.

"At a close hospital like here at Thondwe as he has said that they tend to be shy that people will see them receiving the ARVs so they tend to go to a hospital that is far like at Zomba so that people should not notice, instead the people should just see them (men) boarding a minibus and thinking that maybe they (men) are going in town when actually they are going to the hospital to receive HIV services, so it's because of shyness."

$$
\text { -Zomba, 38, Teacher }
$$

"I think the issue of privacy when working on the part of health workers is what makes people not go for HIV testing because these health workers they don't keep it as a secret. It has spread everywhere and that is another thing which makes us think that I should not go there."

-Machinga, 35, Veterinary Officer
Men also noted drawbacks to accessing VMMC services because they are provided in public locations that do not ensure privacy. And if done in private, they are released on the same day of the procedure when they are in pain and walking awkwardly. Therefore, everyone near the facility knows what they have done.

"To say the truth. This circumcision issue it has reached a point where we are ashamed of it. It has no respect. We plead with the hospital staff to change the approach. When they were starting it was better. They were able to circumcise a person in their car, Mhmm. They stay with the man and they chat with him and they depart in the evening. But as of now, as I am talking now. Last week I went to Mwandama. So it's a public place. They just use a sheet to cover... The same place it's a market place. People are watching and they say 'eh this is the circumcision'."

-Zomba, 48, Foreman

Female providers: Men shunned VMMC due to female providers performing the procedure or female HCWs being in the room. This is rooted in tradition as circumcision is traditionally done by men in the presence of other men. When accessing $\mathrm{VMMC}$, men searched for places where men were administering care.

"The other reason why men tend to be afraid of circumcision is because a lot that are found there are women so they get shy to go to these places but if it was possible for men to conduct circumcision it would have been good, because even if a woman sees you entering that room you tend to be shy."

-Zomba 38, Barber

Long waiting times: The long waiting times at health facilities disrupt men's livelihoods; they are missing work and losing money when having to wait in line for hours for services. This barrier is especially pertinent for those of lower socioeconomic status. 


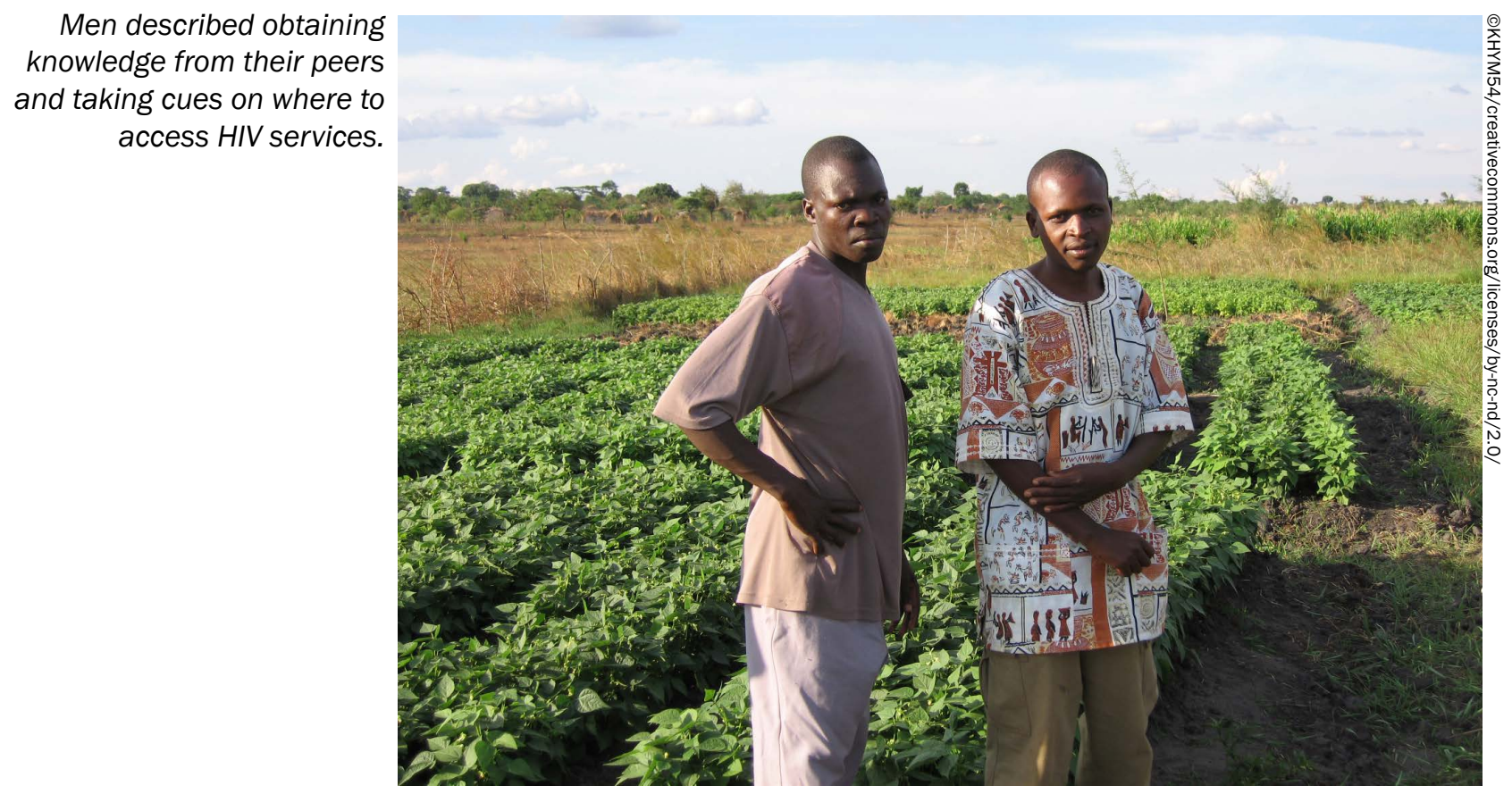

"You find that they can go to a place where there are many people to get tested. They sit on the line where they wait for ages to access these services. When they are in this place time has gone and they cannot find customers to make some money. They realise that this was a result of being delayed at the health facility. While they were delaying there their colleagues that were working maybe have earned money amounting to maybe $\mathrm{K} 3,000$ or the other one has earned K4,000. In the end they just decide that they were just wasting time at the health facility to the point that they make a decision that next time they are called for such servicers they will not go...."

-Machinga, 40, Businessman

\section{Why do men access HIV services?}

Self-care: Men stated that those who accessed HIV services did so because they valued their health and well-being. Therefore, they wanted to know their status and for those who are positive, they want to know how to maintain their health. Additionally, some men are aware of their HIV risk and access testing services as a result.
"We just want to know how we are and to plan to say; what should I ought to be doing? If you know not, it is not good. You can harm yourself because you lack knowledge. You start taking ARVs at later days while your body is too weak because you did not know."

-Machinga, 20, Estate Worker

"Most people get tested so that they should know their HIV status in order for them to plan for their lives. If they tend to be positive they should change their ways and if they also tend to be negative they should also change their ways."

-Zomba, 35, Bike Hire

Peer and partner influence: Men described obtaining knowledge from their peers and taking cues on where to access HIV services. Men also described going for HIV testing due to the encouragement or insistence from their partners, especially a new partner.

"Others also go for testing based on being encouraged by their fellow friends."

-Zomba, 26, Bike Repairer 


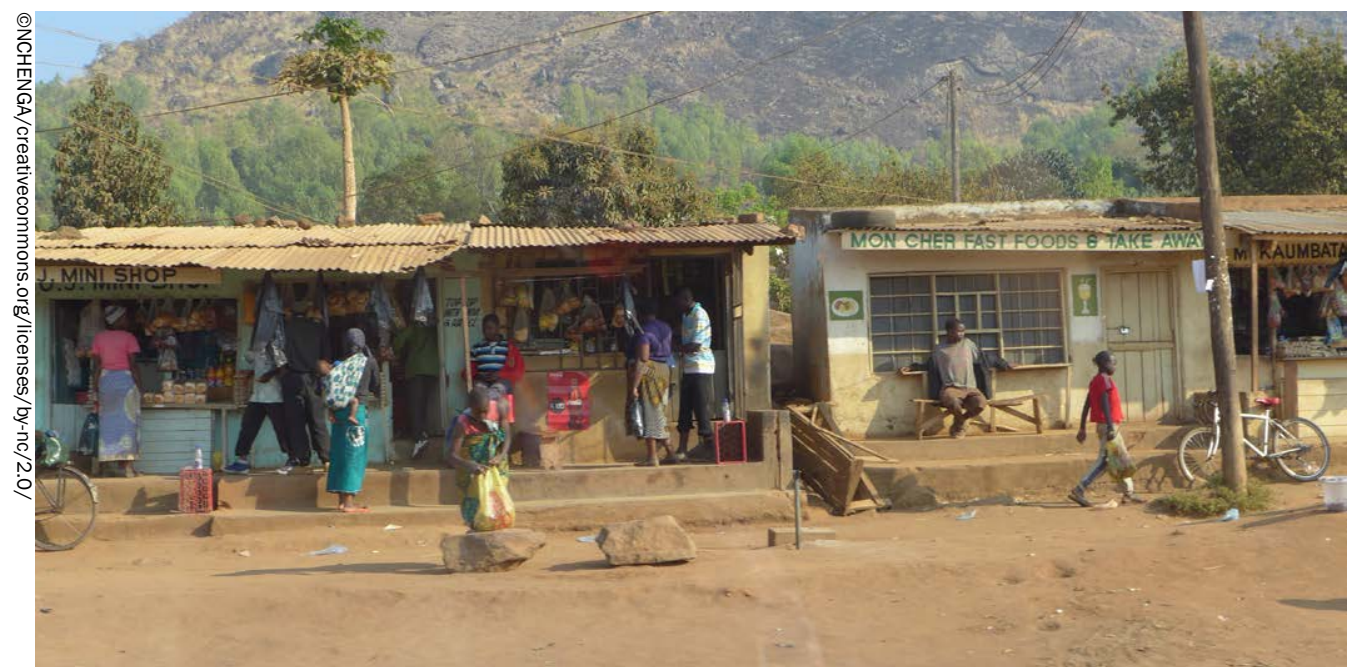

Men want to see more services aimed specifically at men, service locations or times that are only for men, and steps taken to ensure men are comfortable with their care provider.

"Others go for testing when they find a lady (partner) the lady may insist to go for testing."

-Zomba, 30, Bike Hire

\section{What strategies will encourage men to access HIV services?}

\section{Use or incorporate features of initiation camps}

for VMMC. Men explained that circumcision is traditionally done at initiation camps and therefore, a similar set-up would be preferable to attract men to VMMC services. Reasons why they preferred initiation camps include a greater degree of privacy, faster healing time, a longer stay before going home, men are conducting the procedure, and the camps follow tradition. However, some men noted that hospital settings are good if they can incorporate aspects from the initiation camps.

"I think where men can go and get circumcision is through the initiation ceremonies.... The place where you have only men there."

-Zomba, 19, Football Player

"If the man is not ashamed of circumcision and being mentioned, it is good at the hospital; but those who can conduct the operation should be men and it should be a private area. Whereby if a person is coming out there people should not see him coming that side and know that he had the operation."

-Machinga, 23, Vendor

Greater consideration of men's needs: Some men discussed that sexual and reproductive health services, including HIV services, are targeted to women and girls. They want to see more services aimed specifically at men, service locations or times that are only for men, and steps taken to ensure men are comfortable with their care provider.

“...a lot of these organizations just focus on girls. So if their interventions target girls the most it is a problem for us as boys to see or find where we fit in as males. Some organizations should concentrate on the other side and attend to the needs of us boys. If this was possible then it would be much better."

-Machinga, 19, Student

"There should be indeed a special place where men of our age can go (to seek HIV services). A special place so a person will be like ok there are only men like us so let's go and seek services. There should not be women there."

-Zomba, 26, Bike Repairer 
Home-based services: To alleviate long waiting times and privacy concerns at health facilities, men suggested that health workers should come to their homes to administer HIV prevention, treatment, and care services. This strategy could be established by partnering with existing community organizations.

"What I wish could be done in the future is put in place people who could come in the community like door to door. I remember in the past there were some people who were doing HIV testing right away at their door steps."

-Machinga, 36, Teacher

\section{Leverage technology and media for HIV}

messaging: While mass media is already used for HIV messaging, men noted that other types of technology are becoming increasingly common. They cited the internet as an easy and useful source for accessing information about HIV and at times, preferable over standard group-based education forums. Therefore, finding ways to use the internet to reach men could increase their use of services.

"I just wanted to add about the internet that it is a good method to get the information because we can have the questions of which if we can go another meetings they can be talking about the information we already got. Therefore, these meetings are like they are just making noise because what they are talking is already known to us. When you are using the internet you just check the information which is there and if you have questions you can do so that other people can answer you. Therefore, you go direct where you want to know."

-Machinga, 52, Teacher

Focus on youth: Men discussed the importance of reaching young men with HIV education and prevention information and services. They thought that young men do not have the proper education or do not have activities that prevent them from engaging in HIV risk behaviors. They mentioned
HIV education for youth and ensuring options to engage youth in low-risk activities outside of school.

"The method that can help us is to meet with youths often. We meet and we discuss the dangers of HIV. This is one method that can help us to prevent HIV. If we have non-governmental organizations where we can meet with them to discuss HIV-related issues. This way, it can help the youths to protect themselves from HIV and its causes."

-Zomba, 27, Grocery Shop Worker

"In our community we have to have youth clubs or groups where we can meet and discuss things that have to do with HIV and AIDS."

-Zomba, 19, Businessman

\section{RECOMMENDATIONS}

- To reach the male partners of AGYW, who are diverse in their ages, occupations, and where they meet AGYW, design and implement home, community, and venue-based (e.g., workplace, hotspots) strategies.

- Address HIV stigma and accessibility issues by partnering with community health workers and community organizations, who are viewed as more client-friendly, to provide education and HIV services. Training on providing quality services, including stigma reduction, is needed at health facilities.

- Consider enhancing VMMC services by incorporating features from initiation camps that appeal to men, such as privacy, having male healthcare providers, and longer recovery times before release.

- Engage men of all ages early in the development of HIV prevention, care, and treatment messages and services. Leverage technology and mass media to communicate the messages and promote services. 


\section{REFERENCES}

${ }^{1}$ Ministry of Health, Malawi. 2017. "Malawi Population-based HIV Impact Assessment (MPHIA) 2015-16: First report." Lilongwe: Ministry of Health.

${ }^{2}$ Mensch, Barbara S. and Erica Soler--Hampejsek. 2017. "Rates of HIV and HSV-2 among young people in Machinga, Malawi," Project SOAR Results Brief. Washington, DC: Population Council.

${ }^{3}$ Mills, E. J., N. Ford, and P. Mugyenyi. 2009. "Expanding HIV care in Africa: making men matter," The Lancet 374(9686): 275-6.

${ }^{4}$ Cohen, M. S. et al. 2013. "Antiretroviral treatment of HIV-1 prevents transmission of HIV-1: where do we go from here?," The Lancet 382(9903): 1515-24.

${ }^{5}$ Conly, S. 2016. "Male sex partners of adolescent girls and young women in east and southern Africa: What we know (and don't know)." In: TLR Division Meeting.

\footnotetext{
Suggested citation: Project SOAR. 2018. "Engaging male partners of adolescent girls and young women in HIV services in Malawi: Findings from DREAMS implementation science research," Project SOAR Results Brief. Washington, DC: Population Council.
}

Project SOAR/Population Council

4301 Connecticut Avenue, NW, Suite 280

Washington, DC 20008

Tel: +1202 2379400

e-mail: ProjectSOAR@popcouncil.org

projsoar.org

@Population Council, March 2018 